\title{
Psychiatric Symptoms and Dissociation in Conversion, Somatization and Dissociative Disorders
}

\begin{tabular}{|c|c|}
\hline Journal: & Australian and New Zealand Journal of Psychiatry \\
\hline Manuscript ID: & ANP-2008-00241.R1 \\
\hline Manuscript Type: & Regular Article \\
\hline $\begin{array}{r}\text { Date Submitted by the } \\
\text { Author: }\end{array}$ & $\mathrm{n} / \mathrm{a}$ \\
\hline Complete List of Authors: & $\begin{array}{l}\text { Espirito Santo, Helena; Instituto Superior Miguel Torga, Psicologia; } \\
\text { Universidade do Porto, Instituto de Ciências Biomédicas Abel } \\
\text { Salazar } \\
\text { Abreu, Jose Luis; Universidade de Coimbra, Faculdade de Medicina }\end{array}$ \\
\hline Keywords: & $\begin{array}{l}\text { Conversion disorder, Dissociative disorder, Dissociation, } \\
\text { Somatization disorder, Hysteria }\end{array}$ \\
\hline
\end{tabular}

\section{S) ScholaroNE


Psychiatric Symptoms and Dissociation in Conversion, Somatization and Dissociative

Disorders

Helena Espirito-Santo ${ }^{1}$, PsyD., M. D.

José Luís Pio-Abreu², MD., Phd., Professor

Department of Psychology ${ }^{1}$

Instituto Superior Miguel Torga

R. Augusta, $n^{\circ} 46$

Coimbra, Portugal

And

Instituto de Ciências Biomédicas de Abel Salazar,

Universidade do Porto, Portugal

Hospitais da Universidade de Coimbra ${ }^{2}$

Faculdade de Medicina,

Universidade de Coimbra, Portugal

For submission to:

Australian and New Zealand Journal of Psychiatry

Date:

28 outubro 2008

Corresponding Author: Doutora Helena Espirito Santo

Departmento de Psicologia

Instituto Superior Miguel Torga, Coimbra

Largo da Cruz de Celas, 1

3000-132 Coimbra

Portugal

Tel: $\quad(+351) 239488030$

Fax: (+351) 239488031

Email: helenum@gmail.com

Running Head: Psychiatric Symptoms \& Dissociation 


\begin{abstract}
Objective: Conversion, dissociation and somatization are historically related in the long established concept of hysteria. Somewhere along the way they were separated due to the Cartesian dualistic view. Our aim was to compare these pathologies and investigate whether symptoms of these pathologies overlap in their clinical appearance in a Portuguese sample.
\end{abstract}

Method: Twenty-six patients with conversion disorder, 38 with dissociative disorders, 40 with somatization disorder, and a comparison group of 46 patients having other psychiatric disorders answered questions about dissociation (Dissociative Experiences Scale), somatoform dissociation (Somatoform Dissociation Questionnaire), and psychopathological symptoms (Brief Symptom Inventory).

Results: Dissociative and somatoform symptoms were significantly more frequent in dissociative and conversion disorder than in somatization disorder and controls. There were no significant differences between dissociative and conversion patients.

Conclusions: Conversion disorder is closely related to dissociative disorders. These results support the ICD-10 categorisation of conversion disorder among dissociative disorders and the hypothesis of analogous psychopathological processes in conversion and dissociative disorders versus somatization disorder.

\author{
Keywords Conversion disorder; Dissociative disorder; Somatization disorder, \\ Dissociation; Hysteria
}




\section{Introduction}

Hysteria has been an important and well-accepted disease for 3900 years, with an extraordinary and irregular conceptual evolution that ended in its disappearance from the majority of scientific writings [1]. In 1980, hysteria was replaced by distinct illnesses in the DSM and ICD, namely somatization, dissociative, and conversion. The DSM-IV-TR [2] classifies conversion disorder within somatoform disorders, along with somatization disorder. In the ICD-10 conversion disorder is categorised as a dissociative disorder (keeping its "hysteria" designation), and somatization disorder goes with somatoform disorders [3]. However, many investigators noted the great overlap between dissociative and somatoform disorders, as defined in DSM and ICD [4-8]. Several investigations showed that dissociative disorders may present with somatic symptoms [7, 9-17] and conversion symptoms $[7,10,11,18]$. Conversely, many patients with somatization disorder also have dissociative symptoms $[17,19]$, especially if they have been abused $[17,20]$. Additionally, many patients with conversion disorder report dissociative symptoms [8, 21-23], namely patients with pseudoneurological conversion conditions [24-29]. There is a great overlap between these disorders, and many studies have defended the inclusion of the conversion disorder in the group of dissociative disorders [6, 30, 31], like Pierre Janet's perspective [32]; while others have supported the differentiation between conversion and somatization [33].

Dissociation, somatic and psychological, seems to be the underlying mechanism of these three pathologies. The mechanism of psychoform dissociation involves the loss of the integration of consciousness, memory, identity, and perception of the environment [2] (American Psychiatric Association, 1994). Somatoform dissociation is viewed as the lack 
of integration of somatic experiences, functions and responses [34-38]. The most extensively employed self-report measures of dissociation, the Dissociative Experiences Scale (DES) [39] and Somatoform Dissociation Questionnaire (SDQ-20) [36], were developed to measure psychoform and somatoform dissociation respectively. As far as we know, no other study has investigated the three hysterical nosological presentations, nor compared them with other psychopathological disorders in terms of somatoform and psychoform dissociation. This study was undertaken to assess the common and different features of somatization, dissociative and conversion disorders, studying the phenomena of psychoform dissociation, somatoform dissociation, and general psychopathology, and to compare them with other psychiatric conditions.

\section{Material and Methods}

We present the cross-sectional and self-report data collected.

\section{Subjects}

We selected 151 patients from amongst 1162 consecutive cases registered between 2005 and 2006 from three mental health centres; they met DSM-IV criteria for conversion disorder $(n=26)$, dissociative disorders $(n=39)$, somatization disorder $(n=40)$ and other psychiatric disorders $(n=46)$. Twenty-seven were inpatients and 123 were outpatients. We ruled out patients with psychotic disorders, substance abuse disorders, bipolar disorder, personality disorders, and those under 18 years old. Expert clinicians with several years of training (mean practice of 19.7 years) performed a longitudinal evaluation using all data available (LEAD methodology) [40]. Because of logistical factors, only the diagnoses of 62 of these patients were confirmed with a Portuguese version of the 
Dissociative Disorders Interview Schedule (DDIS)[41]. Due to discharge, two patients did not fill out the SDQ-20. None of the other psychiatric patients met criteria for any of the above disorders. All patients gave written informed consent, and anonymity was preserved, according to the Code of Medical Ethics of the World Medical Association Declaration of Helsinki.

The demographic characteristics of the samples can be seen in Table 1. There were no significant differences in ages among the four groups $(\mathrm{F}=1.81, \mathrm{df}=3, \mathrm{p}>0.05)$, nor between genders $\left(\chi^{2}=1.14, \mathrm{df}=3, \mathrm{p}>0.05\right)$, marital status $\left(\chi^{2}=3.10, \mathrm{df}=3, \mathrm{p}>0.05\right)$, school years $(\mathrm{F}=1.82, \mathrm{df}=3, \mathrm{p}>0.05)$, or inpatients/outpatients $\left(\chi^{2}=7.07, \mathrm{df}=3, \mathrm{p}>0.05\right)$. Table 2 shows the sub sample diagnosis frequencies.

\section{Instruments}

The Dissociative Experiences scale: Portuguese version. The DES is a self-administered 28-item questionnaire to measure the frequency of dissociative experiences [39], with subjects answering by circling the percentage of time they experience dissociation (from 0 to 100 in increments of $10 \%$ ). The Portuguese version has good reliability (Cronbach's $\square=0.94)[42]$.

The Somatoform Dissociation Questionnaire (SDQ-20) is a 20-item self-administered tool to evaluate the intensity of somatoform dissociation [36]. Reliability of the Portuguese form was 0.88 (Cronbach's $\square$ ) [43].

The Brief Symptom Inventory (BSI) [44] is a 53-item self-report clinical rating scale that measures psychological distress (Global Severity Index) and nine dimensions: somatization, interpersonal sensitivity, anxiety, phobic anxiety, obsessive-compulsive symptoms, depression, hostility paranoid ideation, and psychoticism. We used the 
Portuguese threshold [45] of 1.7 or greater for each subscale as an indication of symptom severity. These symptom subscales do not correspond to psychiatric diagnosis.

Cronbach's alpha for the subscales ranged from 0.62 (phobic anxiety) to 0.80 (somatization).

The Dissociative Disorders Interview Schedule (DDIS) [41] is a 131-item semi-structured interview that identifies all dissociative disorders, somatization disorder, and conversion disorder according to DSM-IV diagnoses, and a Portuguese adaptation (sensitivity rate $84 \%$, specificity $100 \%$, and overall kappa 0.83 ) [46].

\section{Statistical Analysis}

Data were analysed with Statistical Package for the Social Sciences (SPSS 11.0.3, for Mac OS X). Subjects with the four diagnoses were compared with each other according to the frequency (mean DES scores) and severity (above cut-off score 30) of dissociative experiences; mean SDQ-20 scores, and severity; distress and psychopathological symptoms from the BSI. None of these measures were normally distributed, therefore Kruskal-Wallis tests were used, followed by post-hoc Mann-Whitney tests on each pair of groups and adjusted $p$ value with Bonferroni method ( $p$ value divided by the six paired comparisons made; in this way a significant level was set at $\mathrm{p}<0.008$ ).

\section{Results}

Results are described through the DES, SDQ and BSI measures used in this study. Psychoform dissociation - DES 
The DES ratings of all 151 patients ranged from 1.92 to 72.69 , with a mean \pm SD of 26.82 ; there were no significant differences $(U=23.42, p=0.935)$ between the mean DES scores of women $(26.32 \pm 14.03)$ and men $(27.97 \pm 17.55)$ or between single $(26.23 \pm 15.34)$ and married patients $(27.69 \pm 14.90)(\mathrm{U}=2555.50, \mathrm{p}=0.579)$. Inpatients (mean $\pm \mathrm{SD}=$ $30.06 \pm 15.40)$ and outpatients (mean $\pm \mathrm{SD}=26.10 \pm 15.06)$ did not differ significantly $(\mathrm{U}=1425.00, \mathrm{p}=0.249)$. There was no significant correlation between age and the scale scores $(\square=0.138, \mathrm{p}=0.094)$ or between number of school years and scale scores ( $\square=0.102, p=0.214$ ). Thirty-eight percent of the patients got a score of 30 or above. There were no significant differences between higher and lower scores in terms of demographic characteristics.

Mean \pm SD DES scores were higher for the conversion patients, followed by dissociative disorders, somatization, and the comparison group. These scores differed significantly overall $(\mathrm{H}=68.86, \mathrm{df}=3, \mathrm{p}<0.001$, Kruskal-Wallis one-way analysis of variance by ranks $)$. Pairwise post-hoc $U$ tests showed that dissociative and conversion patients did not differ, nor did somatizing patients from the comparison group. The other group comparisons, however, were significantly different. These results are shown in Table 3.

The proportions of patients from the diagnostic categories with above cut-off scores on the DES are presented in Table 4. Conversion and dissociative patients had significantly $(\mathrm{H}=58.73, \mathrm{df}=3, \mathrm{p}<0.001)$ more severe dissociative experiences than patients with somatization or other psychiatric disorders.

Somatoform dissociation-SDQ

The SDQ ranged from 20.00 to 76.00 and had a mean \pm SD of $32.00 \pm 11.29$ for all patients. Women scored $34.32 \pm 11.73$ and men $33.56 \pm 10.30$ and their differences were not 
significant $(U=2145.00, p=0.394)$; single patients scored $33.01 \pm 9.58$ and married $35.67 \pm 13.34$, and their difference was also non-significant $(U=2453.00, p=0.465)$. Inpatients had significantly higher $(\mathrm{U}=1215.00, \mathrm{p}=0.038)$ somatoform dissociation scores (mean $\pm \mathrm{SD}=39.15 \pm 14.21$ ) than outpatients (mean $\pm \mathrm{SD}=32.96 \pm 10.26$ ). There was no significant correlation between scale scores and age $(\square=0.121, \mathrm{p}=0.142)$. However, less educated subjects had higher scores $(\square=-0.231, \mathrm{p}=0.005)$. A score of 35 or above was attained by $38 \%$ of the patients.

Conversion patients also had higher mean \pm SD SDQ scores, followed by dissociatives, then somatizing, and then other psychiatric patients. These scores differed significantly $(\mathrm{H}=20.46, \mathrm{df}=3, \mathrm{p}<0.001)$. The post-hoc Mann-Whitney tests revealed significant group differences between dissociative and somatizing, dissociative and controls, and between conversion and controls. Once again, dissociative and conversion patients did not differ from each other, nor did somatizing from controls. Conversion patients did not differ from somatizing participants (see Table 3).

More conversion patients scored higher than 35, followed by dissociative, then somatization and other psychiatric patients; these differences were significant $(H=20.14$, $\mathrm{df}=3, \mathrm{p}<0.001)($ see Table 4).

\section{Psychopathology}

The BSI data is presented in Table 3. The mean GSI scores were below the 1.7 threshold for the four groups. Conversion patients scored higher than 1.7 in anxiety and obsessivecompulsive symptoms. Dissociative patients had higher levels in obsessive, depression and paranoid symptoms. Somatizing patients scored higher in somatization and obsessive 
symptoms. As a group, patients with other psychiatric disorders did not score high in any subscales. There were no significant differences between any paired groups in mean $\pm \mathrm{SD}$ GSI scores. We found significant differences only in somatization symptoms, with conversion patients and somatization patients revealing higher levels than patients with other psychiatric diagnoses.

\section{Discussion}

The aim of this study has been to analyze the relationship between conversion disorder, dissociative disorders and somatization disorder across the spectrums of psychoform dissociation, somatoform dissociation, and general psychopathology.

As far as we know, there is only one investigation that has compared conversion and somatization disorder with regard to psychoform dissociative symptoms, and reported no significant differences [21]; our results do not support this investigation: the patients with conversion had higher scores.

We found no studies that compared dissociative and somatization disorder, considering psychoform dissociation. Our findings reveal that dissociative patients scored higher than the somatization subjects.

We also found that patients with conversion and dissociative disorder patients differed significantly from somatization ones regarding somatoform dissociative symptoms; no other study measured this aspect.

Our main finding was a closer association between conversion and dissociative disorders, than between conversion and somatization disorder. This result is supported by: (1) greater psychoform and somatoform dissociation in conversion and dissociation; (2) a 
lack of differences between conversion and dissociative disorders using measures of psychoform dissociation, somatoform dissociation and general psychopathology; (3) differences between conversion and somatization disorder in psychoform but not somatoform dissociation. Additionally, there is a common element to the three groups of pathology, and this is the obsessive symptoms.

These are timely findings, considering the discussion regarding somatoform disorder classification. There are both practical $[47,48]$ and theoretical issues [49]. Some argue that conversion is misplaced in DSM-IV $[6,7,8,37]$ and should be reunited with dissociative disorders $[6,7,22,50-52]$ or that it definitely has a dissociative component $[21,23,53]$. We also propose that conversion is re-conceptualised as a particular type of dissociative disorder, with a somatization aspect. We suggest that psychoform and somatoform dissociation are specific mechanisms of dissociative and conversion disorders.

There were some limitations to our study. Given the small sample size, it is possible that some statistically significant differences occurred by chance, thus our conclusions are limited to general trends, and larger replication studies are required.

Also, our demographics are disproportionate in relation to the population; despite the fact that we had no significant differences in the proportions of demographic characteristics across the four groups, this selection bias may limit the generalisation of the study. However, we know that women are more likely to search for medical or psychological help [54] (WHO, 2006), and are usually over-represented in these studies. Moreover, men and women had no significant differences in mean DES or SDQ scores or in the proportion of higher scores. We are aware that younger subjects tend to report higher 
levels of psychological dissociation [34, 55-59] and somatoform dissociation [16, 60].

The same tendency occurs in less educated subjects for somatoform dissociation $[16,60]$. These possible selection biases were controlled: there was no correlation between age or number of school years and scores of the DES or SDQ, except for the proportion of patients with an elevated SDQ score, who were less educated. Thus, it is important to control the level of education in further studies. Some studies show a relationship between being single and psychological dissociation [57-59], and somatoform dissociation [57]. Again, there were no significant differences in mean DES or SDQ scores or in the proportion of higher scores between single and married subjects. A potential bias may have occurred from the self-report measures. It is possible that symptom exaggeration and contamination with social desirability took place, since we only used the structured interview with 62 subjects (41\%). In addition, we recognize that individuals with psychiatric conditions may have a co-morbid dissociative disorder which goes undiagnosed unless a structured interview takes place [61]. Moreover, we used wide psychiatric categories instead of specific diagnosis, which could introduce unmeasured confusion. In fact, it has been demonstrated that conversion disorder could be a heterogeneous diagnostic category [62]. Additionally, the evaluators were not blind to the diagnosis. Therefore, a growing area for replication would be to use structured interviews combined with self-report measures, do more research on specific diseases, and involve blinded interviewers, unaware of the investigation hypothesis.

Despite these limitations, there are also strengths in this study. The participants were inpatients and outpatients: knowing that inpatients are more likely to have psychiatric comorbidity, outpatients could have brought fewer biases. 


\begin{abstract}
We used, as well, a consecutive sampling procedure, which made the sample closer to a community sample.

Finally, this study was the first to explore the three types of hysteria through psychological and somatoform dissociation.
\end{abstract}

Acknowledgements: None 


\section{References}

1. Veith I. Hysteria, the history of a disease. Chicago: The University of Chicago Press, 1965.

2. American Psychiatric Association. Diagnostic and statistical manual of mental disorders. 4th ed., text rev. Washington, D.C: APA, 2000.

3. World Health Organization. The ICD-10, Classification of mental and behavioural disorders, Geneva: WHO, 1994.

4. Cardeña E, Nijenhuis E. Embodied sorrow: a special issue on somatoform dissociation. J Trauma Dissociation 2000; 1: 1-6

5. Lipsanen T, Saarijärvi S, Lauerma H. Exploring the relations between depression, somatization, dissociation, and alexithymia - overlapping or independent constructs? Psychopathology 2004; 37: 200-206

6. Nemiah JC. Dissociation, conversion, and somatization. In: Spiegel D, ed. Dissociative disorders: A clinical review. Lutherville: Sidran Press, 1993: 104-117

7. Saxe GN, Chinman G, Berkowitz R, Hall K, Lieberg G, Schwartz J, Van der Kolk BA. Somatization in patients with dissociative disorders. Am J Psychiatry 1994; 151: $1329-1334$

8. Spitzer C, Spelsberg B, Grabe H-J, Mundt B, Freyberger HJ. Dissociative experiences and psychopathology in conversion disorders. J Psychosom Res 1999; 46: 291-294 
9. Boon S, Draijer N. Diagnosing dissociative disorders in the Netherlands: a pilot study with the structured interview for DSM-III-R dissociative disorders. Am J Psychiatry $1991 ; 148: 458-462$

10. Coons PM. Dissociative disorder not otherwise specified: a clinical investigation of 50 cases with suggestions for typology and treatment. Dissociation 1992; 5: 187-195 11. Coons PM. Psychogenic amnesia: a clinical investigation of 25 cases. Dissociation 1992; 5: 73-79

12. Nijenhuis ERS, Spinhoven P, Van Dyck R, Van der Hart O, Vanderlinden J. Psychometric characteristics of the somatoform dissociation questionnaire: a replication study. Psychother Psychosom 1998; 67: 17-23

13. Nijenhuis ERS, Van Dyck R, Spinhoven P, et al. Somatoform dissociation discriminates among diagnostic categories over and above general psychopathology. Aust N Z J Psychiatry 1999; 33: 511-520

14. Ross CA, Fast E, Anderson G, Auty A, Todd J. Somatic symptoms in multiple sclerosis and MPD. Dissociation 1990; 3: 102-106

15. Ross CA, Miller SD. Reagor P, Bjornson L, Fraser GA, Anderson G. Structured interview data on 102 cases of multiple personality disorder from four Centers. $\mathrm{Am} \mathrm{J}$ Psychiatry 1990; 147: 596-601

16. Sar V, Kundakçı T, Kızıltan E, Bakim B, Bozkurt O. Differentiating dissociative disorders from other diagnostic groups through somatoform dissociation in Turkey. $J$ Trauma Dissociation 2000; 1: 67-80

17. Walker NG, Katon WJ, Neraas K, Jemelka RP, Massoth D. Dissociation in women with chronic pelvic pain. Am J Psychiatry 1992; 149: 534-537 
18. Martínez-Taboas A. Multiple personality disorder in Puerto Rico: analysis of fifteen cases. Dissociation 1991; 4: 189-192

19. Brown RJ, Schrag A, Trimble MR. Dissociation, childhood interpersonal trauma, and family functioning in patients with somatization disorder. Am J Psychiatry 2005; 162: $899-905$

20. Pribor EF, Yutzy SH, Dean JT, Wetzel RD. Briquet's syndrome, dissociation, and abuse. Am J Psychiatry 1993; 150: 1507-1511

21. Guz H, Doganay Z, Ozkan A, Colak E, Tomac A, Sarisoy G. Conversion and somatization disorders: the dissociative symptoms and other characteristics. $J$ Psychosom Res 2004; 56: 287-291

22. Spitzer C, Freyberger HJ, Stieglitz R-D, et al. Adaptation and psychometric properties of the German version of the dissociative experiences scale. J Trauma Stress 1998; 11: 799-809

23. Tezcan E, Atmaca M, Kuloglu M, Gecici O, Buyukbayram A, Tutkun H. Dissociative disorders in Turkish inpatients with conversion disorder. Compr Psychiatry 2003; 44: 324-330

24. Akyüz G, Kugu N, Akyüz A, Dogan O. Dissociation and childhood abuse history in epileptic and pseudoseizure patients. Epileptic Disord 2006; 6: 187-192

25. Bowman ES, Markand ON. Psychodynamics and psychiatric diagnoses of pseudoseizure subjects. Am J Psychiatry 1996; 153: 57-63

26. D' Alessio L, Giagante B, Oddo S, et al. Psychiatric disorders in patients with psychogenic non-epileptic seizures, with and without comorbid epilepsy. Seizure 2006; 15: $333-339$ 
27. Harden CL. Pseudoseizures and dissociative disorders: A common mechanism involving traumatic experiences. Seizure 1997; 6: 151-155

28. Prueter C, Schultz-Venrath U, Rimpau W. Dissociative and associated psychopathological symptoms in patients with epilepsy, pseudoseizures, and both seizure forms. Epilepsia 2002; 43: 188-192

29. Van Merode T, Twellaar M, Kotsopoulos IAW, et al. Psychological characteristics of patients with newly developed psychogenic seizures. J Neurol Neurosurg Psychiatry 2004; 75: 1175-1177

30. Bowman ES. Why conversion seizures should be classified as a dissociative disorder. Psychiatr Clin North Am 2006; 29: 185-211

31. Cardeña E, Spiegel D. Diagnostic issues, criteria and comorbidity of dissociative disorders. In: Michelson LK, Ray WJ, eds. Handbook of dissociation: theoretical, empirical, and clinical perspectives. New York: Plenum, 1996: 227-250.

32. Janet P. The mental state of hystericals. New York: Putnam, 1901.

33. Kent DA, Tomasson K, Coryell W. Course and outcome of conversion and somatization disorders: a four- year follow-up. Psychosomatics, 1995; 36: 138-144 34. Näring G, Nijenhuis ERS. Relationships between self-reported potentially traumatizing events, psychoform and somatoform dissociation, and absorption, in two non-clinical populations. Aust N Z J Psychiatry 2005; 39: 982-988

36. Nijenhuis ERS, Spinhoven P, Van Dyck R, Van der Hart O, Vanderlinden J. The development and psychometric characteristics of the somatoform dissociation questionnaire (SDQ-20). J Nerv Ment Dis 1996; 184: 688-694 
37. Van der Hart O, Van Dijke A, Van Son M, Steele K. Somatoform dissociation in traumatized World War I combat soldiers: A neglected clinical heritage. J Trauma Dissociation 2000; 1: 33-65

38. Waller G, Hamilton K, Elliot P, et al. Somatoform dissociation, psychological dissociation, and specific forms of trauma. J Trauma Dissociation 2000; 1: 81-98

39. Bernstein EM, Putnam FW. Development, reliability and validity of a dissociation scale. J Nerv Ment Dis 1986; 174: 727-735

40. Spitzer RL. Psychiatric diagnosis: are clinicians still necessary? Compr Psychiatry $1983 ; 24: 399-411$

41. Ross CA, Heber S, Norton GR, Anderson G, Anderson D, Barchet P. The dissociative disorders interview schedule: a structured interview. Dissociation 1989; 2: $169-189$

42. Espirito Santo H, Pio Abreu JL. Portuguese validation of the dissociative experiences scale (DES). J Trauma Dissociation in press

43. Espirito Santo H, Pio Abreu JL. Dissociative disorders and other psychopathological groups: exploring the differences through somatoform dissociation questionnaire (SDQ20). Rev Bras Psiquiatr 2007; 29: 354-358

44. Derogatis LR, Melisaratos N. The brief symptom inventory: an introductory report. Psychol Med 1983; 13: 596-605

45. Canavarro MC. Inventário de sintomas psicopatológicos. In: Simões MR, Gonçalves MM, Almeida LS, eds. Testes e provas projectivas em Portugal, vol. 2. Braga: APPORT, 1988: 95-109. 
46. Espirito Santo HA, Madeira F, Pio Abreu JL. Versão portuguesa do dissociative disorders interview schedule (DDIS-P), Estudo preliminar de adaptação a uma amostra da população portuguesa. Rev Port Psiquiatr 2007; 28: 5-17

47. Kendell R, Jablensky A. Distinguishing between the validity and utility of psychiatric diagnoses. Am J Psychiatry 2003; 160: 4-12

48. Wessely S, Nimnuan C, Sharpe M. Functional somatic syndromes: one or many? Lancet 1999; 354: 936-939

49. Mayou RA. Medically unexplained physical symptoms. Br Med J 1991; 303: 534535.

50. Krüger C, Van Staden W. Is conversion a dissociative symptom? Bridging Eastern and Western Psychiatry 2003; 1: 88-94

51. Sar V, Akyüz G, Kundakçi T, Kiziltan E, Dogan O. Childhood trauma, dissociation, and psychiatric comorbidity in patients with conversion disorder. Am J Psychiatry 2004; 161: $2271-2276$

52. Sharpe M, Mayou R. Somatoform disorders: a help or hindrance to good patient care? Br J Med Psychol 2004; 184: 465-467

53. Moene FC, Spinhoven P, Hoogduin K, Sandyck P, Roelofs K. Hypnotizability, dissociation and trauma in patients with a conversion disorder: an exploratory study. Clin Psychol Psychother 2001; 8: 400-410

54. World Health Organization. Gender and women's mental health. Geneva: WHO, 2006. [cited 21 Dec 2006.] Available from http://www.who.int/mental_health/prevention/genderwomen/en/print.html 
55. Dorahy MJ, Lewis CA, Millar RG, Gee TL. Predictors of nonpathological dissociation in Northern Ireland: the affects of trauma and exposure to political violence. J Trauma Stress 2003; 16: 611-615

56. Espirito Santo HMA, Pio-Abreu JL. Demographic and mental health factors associated with pathological dissociation in a Portuguese sample. J Trauma Dissociation 2008; 9: 369-387

57. Maaranen P, Tanskanen A, Kaisa H, et al. The relationship between psychological and somatoform dissociation in the general population. J Nerv Ment Dis 2005; 193 : $690-692$

58. Spitzer C, Barnow S, Grabe H-J, et al. Frequency, clinical and demographic correlates of pathological dissociation in Europe. J Trauma Dissociation 2006; 7: 51-56 59. Seedat S, Stein MB, Forde DR. Prevalence of dissociative experiences in a community sample: relationship to gender, ethnicity, and substance use. The J Nerv Ment Dis 2003; 191: 115-120

60. Maaranen P, Tanskanen A, Haatainen K, Koivumaa-Honkanen H, Hintikka J, Viinamäki H. Somatoform dissociation and adverse childhood experiences in the general population. J Nerv Ment Dis 2004; 192: 337-342

61. Saxe GN, Van der Kolk BA, Berkowitz R, et al. Dissociative disorders in psychiatric inpatients. Am J Psychiatry 1993; 150: 1037-1042

62. Stone J, Sharpe M, Binzer M. Motor conversion symptoms and pseudoseizures: A comparison of clinical characteristics. Psychosomatics 2004; 45: 492-499 
Table 1. Demographic characteristics of psychopathological groups.

\begin{tabular}{|c|c|c|c|c|c|c|c|c|c|}
\hline \multirow[t]{2}{*}{ Groups } & \multirow{2}{*}{$\begin{array}{l}\text { Total } \\
n\end{array}$} & \multicolumn{2}{|c|}{$\begin{array}{l}\text { Age } \\
\text { (years) }\end{array}$} & \multicolumn{2}{|c|}{$\begin{array}{l}\text { Gender } \\
(\mathrm{M} / \mathrm{F})\end{array}$} & \multicolumn{2}{|c|}{$\begin{array}{l}\text { Marital Status } \\
\text { (married/single) }\end{array}$} & \multicolumn{2}{|c|}{$\begin{array}{l}\text { School } \\
\text { Years }\end{array}$} \\
\hline & & $M$ & $S D$ & $n$ & $\%$ & $n$ & $\%$ & $M$ & $S D$ \\
\hline Dissociative Disorders & 39 & 34.0 & 11.7 & $11 / 28$ & $28.2 / 71.8$ & $20 / 19$ & $51.3 / 48.7$ & 9.7 & 4.5 \\
\hline Conversion Disorder & 26 & 27.4 & 8.8 & $6 / 20$ & $23.1 / 76.9$ & $8 / 18$ & $30.8 / 69.2$ & 10.9 & 4.1 \\
\hline Somatization Disorder & 40 & 32.6 & 12.8 & $14 / 26$ & $35.0 / 65.0$ & $15 / 25$ & $37.5 / 62.5$ & 11.4 & 3.7 \\
\hline Other Psychiatric & 46 & 31.5 & 11.3 & $14 / 32$ & $30.4 / 69.6$ & $18 / 28$ & $39.1 / 60.9$ & 11.7 & 4.4 \\
\hline \multicolumn{10}{|l|}{ Disorders } \\
\hline & 151 & 31.7 & 11.5 & $45 / 106$ & $29.8 / 70.2$ & $61 / 90$ & $40.4 / 59.6$ & 10.9 & 4.2 \\
\hline Total & & & & & & & & & \\
\hline
\end{tabular}


Table 2. Frequencies of group pathologies and their main disorder frequencies $(\mathrm{N}=$ 151).

\begin{tabular}{llll}
\hline Group pathologies & Disorders & $\mathbf{n}$ & $\%$ \\
\hline \multirow{2}{*}{ Conversion disorders } & & 26 & 17.2 \\
& Pseudo seizure & 1 & 0.7 \\
& Combination & 3 & 2.0 \\
& Motor & 10 & 6.6 \\
& Sensorial & 12 & 7.9 \\
& & & \\
Dissociative Disorders & & 39 & 25.8 \\
& DDOS & 10 & 6.6 \\
& Fugue & 7 & 5.3 \\
& Amnesia & 11 & 7.3 \\
& Depersonalization & 11 & 7.3
\end{tabular}


Table 3. Psychoform dissociation (DES), somatoform dissociation (SDQ), global severity index (GSI) and psychopathological symptoms in patients with conversion disorder, dissociative disorders, somatization disorder, and the control group $(\mathrm{N}=$ 151).

\begin{tabular}{|c|c|c|c|c|c|c|c|c|c|c|}
\hline \multirow[t]{2}{*}{ Measures } & \multicolumn{2}{|c|}{$\begin{array}{c}\text { Conversion } \\
\text { disorder }(\mathrm{CV}) \\
(\mathrm{n}=26)\end{array}$} & \multicolumn{2}{|c|}{$\begin{array}{l}\text { Dissociative } \\
\text { Disorders } \\
\text { (DD) } \\
(\mathrm{n}=39)\end{array}$} & \multicolumn{2}{|c|}{$\begin{array}{l}\text { Somatization } \\
\text { Disorder (So) } \\
\quad(\mathrm{n}=40)\end{array}$} & \multicolumn{2}{|c|}{$\begin{array}{c}\text { Other } \\
\text { psychiatric } \\
\text { disorders } \\
(\mathrm{OP}) \\
(\mathrm{n}=46)\end{array}$} & \multicolumn{2}{|c|}{$\begin{array}{c}\text { Kruskal- } \\
\text { Wallis } \\
(\mathrm{df}=3)\end{array}$} \\
\hline & \multicolumn{2}{|c|}{ M SD } & M & SD & M & SD & M & $\mathrm{SD}$ & $\mathrm{H}$ & $p$ \\
\hline DES & 43.49 & 12.33 & 36.02 & 10.10 & 19.39 & 11.89 & 18.02 & 8.37 & 68.86 & 0.000 \\
\hline SDQ & 39.76 & 14.15 & 39.28 & 11.88 & 31.81 & 9.16 & 29.61 & 7.06 & 20.46 & 0.000 \\
\hline \multicolumn{11}{|l|}{ BSI } \\
\hline GSI & 1.48 & 0.43 & 1.55 & 0.57 & 1.54 & 0.54 & 1.23 & 0.43 & 10.40 & 0.015 \\
\hline Somatization & 2.00 & 0.92 & 1.05 & 0.78 & 1.74 & 0.75 & 0.89 & 0.59 & 27.30 & 0.000 \\
\hline Interpersonal sensitivity & 1.46 & 0.69 & 1.42 & 0.82 & 1.63 & 0.72 & 1.43 & 0.66 & 1.39 & 0.709 \\
\hline Anxiety & 1.71 & 0.82 & 1.39 & 0.65 & 1.54 & 0.80 & 1.30 & 0.64 & 3.40 & 0.335 \\
\hline Phobic Anxiety & 0.97 & 0.97 & 0.52 & 0.65 & 0.85 & 0.83 & 0.92 & 0.73 & 4.30 & 0.232 \\
\hline Psychoticism & 1.43 & 0.93 & 1.53 & 0.93 & 1.17 & 0.65 & 1.10 & 0.63 & 4.92 & 0.178 \\
\hline Obsessive-compulsion & 1.71 & 0.67 & 1.70 & 0.80 & 1.74 & 0.66 & 1.48 & 0.59 & 2.53 & 0.471 \\
\hline Depression & 1.50 & 0.85 & 1.98 & 1.20 & 1.56 & 0.86 & 1.50 & 0.73 & 1.60 & 0.659 \\
\hline Hostility & 1.06 & 0.68 & 0.97 & 0.78 & 1.32 & 0.87 & 1.09 & 0.67 & 1.52 & 0.679 \\
\hline \multirow[t]{8}{*}{ Paranoid ideation } & 1.69 & 0.69 & 1.78 & 0.77 & 1.59 & 0.68 & 1.37 & 0.58 & 3.95 & 0.267 \\
\hline & \multicolumn{6}{|c|}{ Pairwise Post-hoc Mann-Whitney } & & & & \\
\hline & \multicolumn{6}{|c|}{ DES: $\mathrm{CV}>\mathrm{So} * * * ; \mathrm{CV}>\mathrm{OP} * * ; \mathrm{DD}>\mathrm{So} * * * ; \mathrm{DD}>\mathrm{OP} * * *$} & & & & \\
\hline & \multicolumn{6}{|c|}{ Other comparisons non significant. } & & & & \\
\hline & \multicolumn{6}{|c|}{$\mathrm{SDQ}: \mathrm{CV}>\mathrm{OP} * * ; \mathrm{DD}>\mathrm{So} *$; $\mathrm{DD}>\mathrm{OP} *$} & & & & \\
\hline & \multicolumn{6}{|c|}{ Other comparisons non significant. } & & & & \\
\hline & \multicolumn{6}{|c|}{ GSI: comparisons non significant. } & & & & \\
\hline & \multicolumn{6}{|c|}{ Somatization: $\mathrm{Co}>\mathrm{OP} * * *, \mathrm{So}>\mathrm{OP} * * *$} & & & & \\
\hline
\end{tabular}


Table 4. Percentages of cases of diagnostic categories scoring above the cut-offs on the Dissociative Experiences Scale (DES) and the Somatoform Dissociation Questionnaire (SDQ-20) (N=151).

\begin{tabular}{|c|c|c|c|c|}
\hline \multirow[b]{2}{*}{ Pathologies } & \multicolumn{2}{|l|}{$\mathrm{DES} \geq 30$} & \multicolumn{2}{|c|}{$\mathrm{SDQ} \geq 35$} \\
\hline & $\mathrm{n}$ & $\%$ & $\mathrm{n}$ & $\%$ \\
\hline Conversion disorders $(\mathrm{CV})$ & 29 & 78.4 & 22 & 59.5 \\
\hline Dissociative disorders (DD) & 18 & 69.2 & 15 & 60.0 \\
\hline Somatization disorder (So) & 6 & 15.0 & 10 & 25.0 \\
\hline Other psychiatric disorders (OP) & 5 & 10.9 & 10 & 21.7 \\
\hline \multirow[t]{6}{*}{ Kruskal-Wallis $(\mathrm{df}=3)$} & $58.73 * * *$ & & 20 . & \\
\hline & \multicolumn{4}{|c|}{ Pairwise Post-hoc Mann-Whitney } \\
\hline & \multicolumn{4}{|c|}{ DES: $\mathrm{CV}>\mathrm{So} * * * ; \mathrm{CV}>\mathrm{OP} * * * ; \mathrm{DD}>\mathrm{So} * * * ; \mathrm{DD}>\mathrm{OP} * * *$} \\
\hline & \multicolumn{4}{|c|}{ Other comparisons non significant. } \\
\hline & \multicolumn{4}{|c|}{ SDQ: $\mathrm{CV}>\mathrm{So}^{*} ; \mathrm{CV}>\mathrm{OP} * * ; \mathrm{DD}>\mathrm{So} *$; $\mathrm{DD}>\mathrm{OP} * * *$} \\
\hline & \multicolumn{4}{|c|}{ Other comparisons non significant. } \\
\hline
\end{tabular}

